\title{
Comparison on Travel Scheduling between Driving and Walking Trips by Habitual Car Users
}

\section{Sheila Ferrer • Tomás Ruiz}

Abstract Research on walking behavior has become increasingly more important in the field of transportation in the past decades. However, the study on the factors influencing the scheduling decisions related to walking trips and the exploration of the differences between travel modes has not been conducted yet. This paper presents a comparison of the scheduling and rescheduling decisions associated with car driving trips and walking trips by habitual car users using a data set collected in Valencia (Spain) in 2010. Bivariate probit models with sample selection are used to accommodate the influence of pre-planning on the decision to execute a travel as planned or not. The explicative variables considered are socio-economic characteristics of respondents, travel characteristics, and facets of the activity executed at origin and at destination including the scheduling decisions associated with them. The results demonstrate that a significant correlation exists between the choice of pre-planning and rescheduling for both types of trips. However, some interesting differences arise regarding the scheduling and rescheduling decision processes between travel modes: car driving trips are more pre-planned than walking trips, and if the latter are pre-planned, they are more likely to be carried out without any modification. Additionally, an important result indicates the effect of the proximity of the residence to the city centre of Valencia on the scheduling decisions of walking trips: those living closer to the city centre pre-plan more walking trips.

Keywords Activity-travel scheduling, car driving trips, walking trips, scheduling decisions, bivariate probit, sample selection

\footnotetext{
Sheila Ferrer (corresponding author), PhD Candidate, Transport Department, Universitat Politècnica de València, Camino de Vera s/n, 46022 Valencia, Spain

E-Mail: shferlo@upv.es, Tel: (+34) 963877365

Tomás Ruiz , Associate Professor, Transport Department, Universitat Politècnica de València, Camino de Vera $\mathrm{s} / \mathrm{n}, 46022$ Valencia, Spain

E-Mail: truizsa@tra.upv.es, Tel: (+34) 963877370, Fax: (+34) 963877370
} 


\section{Introduction}

Urban mobility is responsible for about a quarter of $\mathrm{CO}_{2}$ emissions from transportation and promoting more sustainable behavior is among the objectives of the European Union (EC 2011). Walking is an environmentally friendly travel mode and one of the alternatives to individual conventional transportation. In the case of Spain, walking is the most important mode of transportation for trips other than commuting, and non-motorized trips (walking and cycling) constitute $23 \%$ of commuting trips (Monzón et al. 2013). The importance of active transportation is not only related to environment but to health: countries where active transportation is most common have the lowest obesity rates (Bassett et al. 2008).

There is considerable research in the field of walking as a transportation mode. Some recent efforts are focused on the understanding of pedestrian route choice (Weinstein et al. 2008; Borst et al. 2009; Zielstra and Hartwig 2012; Canca et al. 2013), pedestrian level of service (Asadi-Shekari et al. 2013), the link between the built environment and walking (Greenwald and Boarnet 2002; Cao et al. 2006; Kelly et al. 2011; Yin 2013; Guinn and Stangl 2014) and other factors influencing walking frequency (Lachapelle and Noland 2012), among others studies. However, past research has not focused on the understanding of factors influencing the scheduling and rescheduling of walking trips.

The interest in the analysis of activity scheduling decision processes is explained because the success of transportation policies depends on how people schedule and change their activity-travel patterns. Over the last few decades there have been making significant advances in the development of activity-based travel demand models. The activity based approach is intended to capture the influences of different policy variables on various stages of activity-travel decision making processes (Habib et al. 2012). More specifically, the activity scheduling process is defined as the planning and execution of activity-related decisions over time within a household (Doherty 2000). In the scheduling process, the pre-planning of activities is followed by a more dynamic and continuous series of short-term pre-planning, 
impulsive and adaptative decision making leading up to the actual execution of activities (Doherty and Miller 2000).

This paper offers a contribution to existing research by studying the factors affecting the scheduling decisions related to walking trips. This study also compares the factors influencing the travel scheduling of car driving and walking trips by habitual car users using a data set recently collected in Valencia (Spain). The study considers how scheduling decisions are determined by individual and household characteristics, characteristics of the main activity at origin and at destination, and the scheduling decisions associated with them.

The study aims to address the following questions: (1) Are travel scheduling and rescheduling decisions related to car driving trips different from those related to walking trips by habitual car users? (2) Is there a significant and similar correlation between the choice of pre-planning and rescheduling in both types of trips? (3) Are socio-economic characteristics equally important in the scheduling and rescheduling decision processes of car driving trips and walking trips? (4) Are the characteristics of the activity at origin and destination of the trip relevant to the scheduling and rescheduling of both types of trips?

The rest of the paper is organized as follows. The next section reviews the literature on activity scheduling models. Section 3 describes the panel survey and data sample used for the analyses. Section 4 presents the modelling approach used in this study, a bivariate probit model with sample selection, and the results are discussed. A summary of the main findings and policy implications concludes this paper.

\section{Literature review}

Activity scheduling models

Several models have been developed to represent the process of activity scheduling and to predict how individuals might adjust their activities and travelling when faced with policy changes, scheduling conflicts, and unexpected events. Examples of these models include STARCHILD (Recker et al. 1986), SCHEDULER (Golledge et al. 1994), ALBATROSS 
(Arentze and Timmermans 2000), TASHA (Roorda et al. 2005). More recently, other models have been developed in an effort to address a framework for the activity scheduling process, the random utility maximization based dynamic activity scheduling model (Habib 2011), ADAPTS (Auld and Mohammadian 2012) and two new multi-state super-network models (Liao et al. 2013; Xiao and Lam 2014), among others.

For example, one of the most recent efforts is the ADAPTS model (Agent-based Dynamic Activity Planning and Travel Scheduling), developed by Auld and Mohammadian (2012) to simulate planning, scheduling and execution of activity patterns in an integrated dynamic framework. This framework allows the simulation of activity planning in a nonsequential order, where the individual attribute choice decision can be made at any time before the activity is executed and in any order. Some of the individual decisions included in this model are: destination choice, starting time, travel mode and duration, etc.

Scheduling and rescheduling dynamics

Empirical analysis of some of the dynamics aspects of activity scheduling have been conducted by Doherty (2005), Joh et al. (2005), Mohammadian and Doherty (2006), Clark and Doherty (2008), Nijland et al. (2009), Ruiz and Roorda (2008, 2011). Also a set of activity conflict resolution models have been created to address how an individual reschedules his/her activities when conflicts arise, including Ruiz and Timmermans (2006), Nijland et al. (2009) among others.

Some studies are aimed at improving the understanding of factors affecting the activity-travel scheduling and rescheduling behavior. Mohammadian and Doherty (2006) developed a model to predict the duration of time between planning and execution of activities and found that longer activities tend to be planned further ahead. Joh et al. (2005) analyzed the attributes influencing the probability of an activity episode to be rescheduled using a multinomial logistic regression and found that activities planned to be executed in the afternoon and evening and those performed at home were more likely to be modified. Nijland 
et al. (2009) performed an experiment to estimate parameters determining the rescheduling of activities and associated travel in response to unforeseen events. Van Bladel et al. (2009) studied which activities are planned beforehand (scheduled days or weeks in advance) and which are spontaneously executed (executed without planning). They also analyzed whether planned activities are executed with or without modifications in any of their attributes and the factors influencing these rescheduling decisions. Both analyses were carried out using two separate mixed logit models. Van den Berg et al. (2010) focused on the planning of social activities as a function of personal and household characteristics, social activity characteristics and persons involved.

Recently, García-Garcés and Ruiz (2013) found a significant correlation between the decision to execute or not a pre-planned activity-travel episode and the decision to execute that activity episode as pre-planned or with modifications. Bivariate probit sample selection models were used to take into account potential self-selectivity bias in the decision process.

All the studies discussed above deal with some specific aspects of the activity-travel scheduling and rescheduling process. Recently, Ferrer and Ruiz (in press) focused on the analysis of the scheduling and rescheduling decisions associated with car driving trips by habitual car users, using a bivariate probit model with sample selection to consider the influence of pre-planning on the decision to execute a trip as planned or not. The explicative variables included in the model are individual and household characteristics of respondents, trip characteristics and facets of the activity at origin and at destination.

In this paper, we focus our research on the comparison of habitual car users' scheduling and rescheduling travel decisions related to car driving and walking trips. This is the first study developed to understand the differences in travel scheduling decisions by habitual car users between car driving and walking trips. Two bivariate probit models with sample selection are used: one for car driving trips and another for walking trips. In addition, to accommodate heterogeneity effects, random parameters are used in both models. 


\section{Data characteristics}

\section{Data collection}

The dataset used in this study was collected in the first wave of an activity-travel panel survey conducted in Valencia (Spain) in autumn 2010 from 166 adults (Ruiz et al. 2012; Ferrer and Ruiz, in press). The aim of this activity-travel panel survey was to study the influence of travel behavior change programs on both travel mode choice and activity-travel scheduling process of habitual drivers. Thus, the panel survey was designed to collect multiday information on observed activity-travel patterns both in planning and execution stages.

The recruitment of habitual car users for the panel survey was carried out at parking lots located throughout the city of Valencia (Ferrer and Ruiz, in press). The survey methodology consisted in three phases (García-Garcés and Ruiz 2013): a preliminary faceto-face interview to generate a pre-planned activity-travel agenda, the completion of an activity-travel diary implemented on mobile phones to collect characteristics of activities and trips as they were executed; and in-depth telephone interviews to inquire respondents on the reasons for the differences between the pre-planned agenda and observed activities and travels.

In the face-to-face interview, demographic and socioeconomic information was collected and respondents were asked to generate a pre-planned agenda for the week starting the day after the interview. Participants should define all activities and trips already scheduled using paper and pencil. The following attributes of each pre-planned activity/travel were asked to be defined if known (García-Garcés and Ruiz 2013): type of activity/mode of transport, starting time, duration, location/destination, number of household members and number of non-household members involved. In this first face-to-face interview, mobile phones were delivered to participants, which included activity-travel diaries implemented to collect activities and trips as they were executed. A wide range of activity types were available to be selected in the phone survey and organized into eight main groups (Basic Needs, Work/school, Shopping, Household Obligations, Leisure, Services, Social and Other) 
and thirty-seven specific activity types (Sleep, breakfast/lunch/dinner, personal care, working, tele-working, attending classes, etc.).

During the research week, participants were asked to carry the mobile devices with them and register the activities and trips performed in real time. They had to switch on the mobile phone when they woke up in the morning, and select the first activity type, location, estimated duration and with whom it was undertaken. Every time a participant confirmed that an activity or travel had ended, a real-time e-mail containing all the data of the episode executed was sent to a central server where observed activity-travels were manually compared with preplanned activity-travels. Additionally, participants were contacted by phone two to three times during the research week to inquire on the reasons for the observed changes in the attributes between pre-planned and executed activities and trips and to complete the agenda of the following days as had been previously decided. For further details about the data collection methodology the reader can consult Ferrer and Ruiz (in press).

\section{Data sample}

The panel survey was formed by 166 respondents, who provided a total of 21163 episodes of activities and trips. For the purpose of this study, only car driving trips and walking trips are considered, which constitute $84 \%$ of all recorded trips. After removing poor-quality records, 2976 car driving trips and 843 walking trips together with the main activity at origin and at destination are included in the final data set for modelling and research purposes of this paper.

The socio-demographics statistics are similar to the distribution of gender and occupation in Valencia in 2010, except for the low number of people over 50 . The sample consists of 166 respondents ( $47 \%$ female, $53 \%$ male) that are between 18 and 70 years of age (45\% between 18 and 30, 47\% between 31 and 50, and $8 \%$ over 50 ). The education status of the sample is as follows: $5 \%$ have an elementary education level, $32 \%$ secondary 
education level, $14 \%$ post-secondary non-university level, $19 \%$ bachelor's degree, $30 \%$ master's degree or PhD. In terms of the activity status, $71 \%$ of respondents are employed, $24 \%$ studying and $5 \%$ unemployed or retired. In addition, $40 \%$ of respondents are living within $2.5 \mathrm{~km}$ of the city centre of Valencia.

\section{Descriptive statistics}

The manual comparison of executed travel episodes with those pre-planned in the agenda resulted in four types of scheduling decisions (Ferrer and Ruiz, in press): executed as preplanned, pre-planned and executed with changes (modified or rescheduled episodes), added spontaneously the same day (added episodes) and pre-planned but not executed (deleted episodes). However, with the aim to simplify the analysis, the data used are only executed trips, not deleted episodes. Thus, only three types of trip scheduling decisions are considered: executed as pre-planned, pre-planned and modified, and spontaneously added.

In practice, activities or trips are considered modified if one or more of its attributes are rescheduled:

- The pre-planned starting time or duration differs more than 30 minutes from the executed starting time or duration.

- The specific activity type executed is different from the pre-planned type but remains in the same main group of activities. For example, an activity is modified if it was scheduled as attending classes but it was executed as studying since both specific activities belong to the same group: work/study. Additionally, a trip is modified if it was planned to be undertaken by a specific travel mode but it was executed in a different mode of transportation.

- The location of the activity or the destination of the executed trip are different from those pre-planned.

- The number of household members/non-household members pre-planned to be involved in the activity or trip differ from the number present in the execution. 
For the identification of the main activity executed at origin and the main activity executed at destination, the criteria was to choose the longest activity in duration within two hours before the starting time of the trip and the longest activity within two hours after ending the trip.

The following tables show the average weekly car driving trips and walking trips per person and scheduling decisions by demographic and socio-economic characteristics.

Table 1 Average Weekly Car Driving Trips Per Person and Scheduling Decisions by Demographic and Socio-economic Characteristics

\begin{tabular}{|c|c|c|c|c|c|c|c|}
\hline & \multirow{2}{*}{ Average } & \multicolumn{6}{|c|}{ Scheduling Decisions } \\
\hline & & $\begin{array}{l}\text { Executed as } \\
\text { Pre-Planned }\end{array}$ & $\%$ & Modified & $\%$ & Added & $\%$ \\
\hline \multicolumn{8}{|l|}{ Gender } \\
\hline Male & 19.31 & 6.47 & 33.5 & 4.91 & 25.4 & 7.93 & 41.1 \\
\hline Female & 16.37 & 5.54 & 33.8 & 4.06 & 24.8 & 6.77 & 41.3 \\
\hline \multicolumn{8}{|l|}{ Age } \\
\hline $18-30$ & 17.16 & 4.87 & 28.4 & 4.35 & 25.3 & 7.95 & 46.3 \\
\hline $31-50$ & 18.42 & 7 & 38.0 & 4.76 & 25.8 & 6.67 & 36.2 \\
\hline$>50$ & 19.38 & 6.9 & 35.7 & 4 & 20.6 & 8.46 & 43.7 \\
\hline \multicolumn{8}{|l|}{ Education Level } \\
\hline Primary & 22 & 8 & 36.4 & 3.57 & 16.2 & 10.43 & 47.4 \\
\hline Secondary & 17.22 & 6.13 & 35.6 & 3.87 & 22.5 & 7.22 & 41.94 \\
\hline $\begin{array}{l}\text { Post-secondary non- } \\
\text { university level }\end{array}$ & 17.05 & 5.95 & 34.9 & 4.82 & 28.3 & 6.27 & 36.8 \\
\hline Bachelor & 18.26 & 4.68 & 25.6 & 4.84 & 26.5 & 8.74 & 47.9 \\
\hline Master's Degree / PhD & 18.29 & 6.5 & 35.5 & 4.98 & 27.2 & 6.81 & 37.2 \\
\hline \multicolumn{8}{|l|}{ Activity Status } \\
\hline Working & 18.88 & 6.79 & 35.95 & 4.97 & 26.30 & 7.13 & 37.75 \\
\hline Studying & 14.90 & 4.28 & 28.69 & 3.28 & 21.98 & 7.35 & 49.33 \\
\hline Other & 19.00 & 3.63 & 19.08 & 4 & 21.05 & 11.38 & 59.87 \\
\hline \multicolumn{8}{|l|}{ Marital Status } \\
\hline Married or Couple & 18.56 & 6.75 & 36.44 & 4.66 & 25.17 & 7.11 & 38.39 \\
\hline Divorced or Single & 17.37 & 5.36 & 30.86 & 4.37 & 25.17 & 7.64 & 43.98 \\
\hline \multicolumn{8}{|c|}{ Distance from household to city centre } \\
\hline$<2.5 \mathrm{~km}$ & 16.66 & 5.67 & 34.06 & 4.00 & 24.02 & 6.99 & 41.93 \\
\hline$>2.5 \mathrm{~km}$ & 18.67 & 6.24 & 33.42 & 4.81 & 25.77 & 7.62 & 40.82 \\
\hline
\end{tabular}

The results presented in Table 1 are related to trips by car. The analysis of the results presented show that, on average, males undertake more trips by car per week (19.31) than females (16.37). However, there are not significant differences at the scheduling level: both 
pre-plan about $60 \%$ of weekly trips by car. The average number of weekly car trips by age shows adults over 50 make more weekly person trips by car. Additionally, those between 30 and 50 pre-plan about $64 \%$ of their trips and execute as pre-planned the higher percentage of trips. On average, those with higher education make more weekly trips. In addition, together with those with a post-secondary non-university level, respondents with the highest educational level schedule more trips by car than the rest and they spontaneously add only a few. Workers make more trips than students and tend to schedule a higher percentage of their car trips compared with respondents who are unemployed. Retired and unemployed execute spontaneously the highest number of trips by car. Those married or living in couple undertake slightly more trips than those who are divorced or single, and they also present higher percentages of pre-planned trips.

The descriptive results presented in Table 2 are associated to walking trips. In contrast with the results obtained for car trips, walking trips are more likely to be added without pre-planning and less likely to be modified once pre-planned in the agenda. In addition, gender might have a significant effect in the scheduling process: women schedule more than half of the walking trips while men pre-plan less walking trips. Men modify walking trips in percentage more than women and add more than half of the trips. Similar results are found for trips by private car. Those aged between 30 and 50 , schedule more than half of their walking trips compared to younger and older people who are more likely to add half of their trips. These results are in line with those for car trips.

On average, those with higher education make more weekly trips, both walking and by car. To have a higher education is likely to influence the scheduling process: in percentage these respondents schedule more than $50 \%$ of these trips. Workers schedule a higher percentage of their trips compared to those not working (students, unemployed and retired) who add more than $50 \%$ of their trips. These findings are in line with the results for car trips. Those married or living in couple undertake slightly more trips than those who are divorced or single, and they also present higher percentages of pre-planned trips. Equivalent results are those obtained for car trips. 
Table 2 Average Weekly Walking Trips Per Person and Scheduling Decisions by Demographic and Socio-economic Characteristics

\begin{tabular}{|c|c|c|c|c|c|c|c|}
\hline & \multirow[b]{2}{*}{ Average } & \multicolumn{6}{|c|}{ Scheduling Decisions } \\
\hline & & $\begin{array}{l}\text { Executed as } \\
\text { Pre-Planned }\end{array}$ & $\%$ & Modified & $\%$ & Added & $\%$ \\
\hline \multicolumn{8}{|l|}{ Gender } \\
\hline Male & 4.48 & 1.22 & 27.15 & 0.85 & 19.04 & 2.41 & 53.81 \\
\hline Female & 5.60 & 2.15 & 38.44 & 0.85 & 15.10 & 2.60 & 46.45 \\
\hline \multicolumn{8}{|l|}{ Age } \\
\hline $18-30$ & 4.52 & 1.19 & 26.25 & 0.95 & 20.94 & 2.39 & 52.80 \\
\hline $31-50$ & 5.23 & 2.04 & 38.97 & 0.76 & 14.46 & 2.44 & 46.57 \\
\hline$>50$ & 6.46 & 2.08 & 32.14 & 0.85 & 13.10 & 3.54 & 54.76 \\
\hline \multicolumn{8}{|l|}{ Education Level } \\
\hline Primary & 3.57 & 0.43 & 12.00 & 0.57 & 16.00 & 2.57 & 72.00 \\
\hline Secondary & 4.45 & 1.49 & 33.48 & 0.61 & 13.66 & 2.35 & 52.86 \\
\hline $\begin{array}{l}\text { Post-secondary non- } \\
\text { university level }\end{array}$ & 4.41 & 1.64 & 37.11 & 0.55 & 12.37 & 2.23 & 50.52 \\
\hline Bachelor & 6.93 & 2.30 & 33.17 & 1.27 & 18.27 & 3.37 & 48.56 \\
\hline Master's Degree / PhD & 5.71 & 1.89 & 33.21 & 1.17 & 20.44 & 2.65 & 46.35 \\
\hline \multicolumn{8}{|l|}{ Activity Status } \\
\hline Working & 5.29 & 1.81 & 34.08 & 0.89 & 16.96 & 2.59 & 48.96 \\
\hline Studying & 3.85 & 1.15 & 29.87 & 0.68 & 17.53 & 2.03 & 52.60 \\
\hline Other & 6.5 & 2.00 & 30.77 & 1.00 & 15.38 & 3.50 & 53.85 \\
\hline \multicolumn{8}{|l|}{ Marital Status } \\
\hline Married or Couple & 5.20 & 1.93 & 37.02 & 0.83 & 15.87 & 2.45 & 47.11 \\
\hline Divorced or Single & 4.83 & 1.41 & 29.16 & 0.87 & 18.07 & 2.55 & 52.77 \\
\hline \multicolumn{8}{|c|}{ Distance from household to city centre } \\
\hline$<2.5 \mathrm{~km}$ & 5.89 & 2.28 & 38.72 & 1.08 & 18.38 & 2.53 & 42.90 \\
\hline$>2.5 \mathrm{~km}$ & 4.49 & 1.29 & 28.81 & 0.71 & 15.89 & 2.48 & 55.30 \\
\hline
\end{tabular}

The scheduling decisions studied also depend on characteristics of the main activity at origin and destination. The frequency of car and walking trips by activity at destination and the type of scheduling decisions in percentage is presented in Table 3. Car trips to undertake basic needs, work or study-related activities and household obligations are mainly preplanned and basic needs-related trips are the most modified among them. Trips for shopping and carrrying out service activities, such as medical or banking appointments, are the most spontaneously added. The characteristics of the scheduling decisions related to walking trips are similar to car trips: trips to undertake "mandatory" activities (work or study, household obligations) are scheduled in advance, together with those basic needs-related, and 
shopping trips are the least pre-planned. The main difference observed between car trips and walking trips is that walking trips are mostly executed as pre-planned once scheduled in the agenda, while car trips are more sensitive to changes.

Table 3 Scheduling Decisions of Car Driving Trips and Walking trips by Activity at Destination

\begin{tabular}{lcccccccc}
\hline & \multicolumn{3}{c}{ Car driving trips } & \multicolumn{5}{c}{ Walking trips } \\
\cline { 2 - 10 } & Frequency & $\begin{array}{c}\text { Executed as } \\
\text { Pre-Planned } \\
(\%)\end{array}$ & $\begin{array}{c}\text { Modified } \\
(\%)\end{array}$ & $\begin{array}{c}\text { Added } \\
(\%)\end{array}$ & Frequency & $\begin{array}{c}\text { Executed as } \\
\text { Pre-Planned } \\
(\%)\end{array}$ & $\begin{array}{c}\text { Modified } \\
(\%)\end{array}$ & $\begin{array}{c}\text { Added } \\
(\%)\end{array}$ \\
\hline Activity type & & & & & & & & \\
Basic needs & 709 & 29.6 & 31.45 & 38.93 & 241 & 30.29 & 19.92 & 49.79 \\
Work/study & 770 & 53.77 & 25.97 & 20.26 & 148 & 60.14 & 20.95 & 18.92 \\
Shopping & 176 & 9.09 & 18.75 & 72.16 & 89 & 10.11 & 8.99 & 80.90 \\
Household & 449 & 43.43 & 25.17 & 31.40 & 100 & 42.00 & 18.00 & 40.00 \\
obligations & 390 & 21.03 & 26.41 & 52.56 & 107 & 25.23 & 17.76 & 57.01 \\
Leisure & 78 & 10.26 & 14.10 & 75.64 & 38 & 31.58 & 7.89 & 60.53 \\
Service & 364 & 19.23 & 17.03 & 63.74 & 82 & 24.39 & 8.54 & 67.07 \\
Social & 40 & 15.00 & 10.00 & 75.00 & 26 & 11.54 & 26.92 & 61.54 \\
Other & & & & & & & & \\
\hline
\end{tabular}

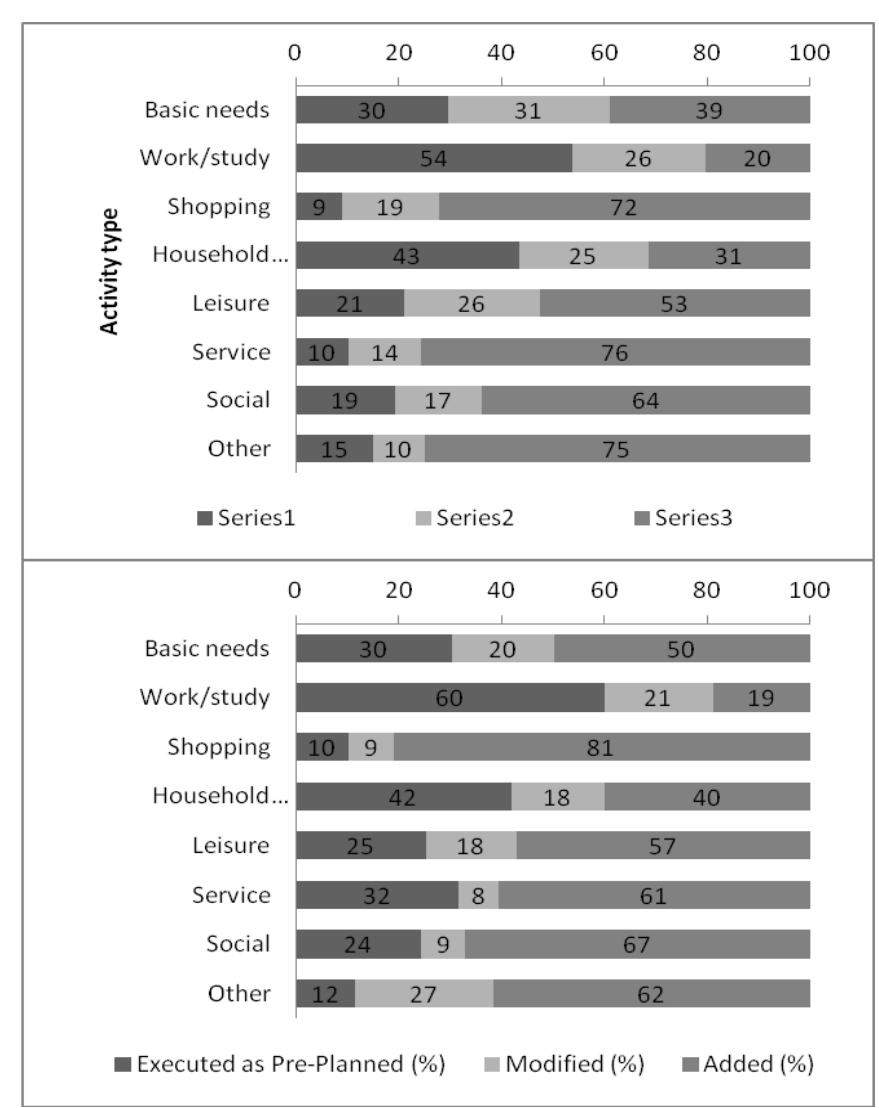


Table 4 presents the frequency of car and walking trips by the type of activity at origin and the type of scheduling decisions in percentage. Trips related to activities at origin like executing basic needs, work or study-related and household obligations are pre-planned and generally executed without any modification. In addition, after shopping, car and walking trips are more spontaneously added but if pre-planned, walking trips are the least modified.

Table 4 Scheduling Decisions of Car Driving Trips and Walking Trips by Activity at Origin 


\begin{tabular}{lcccccccc} 
& Frequency & $\begin{array}{c}\text { Executed as } \\
\text { Pre-Planned } \\
(\%)\end{array}$ & $\begin{array}{c}\text { Modified } \\
(\%)\end{array}$ & $\begin{array}{c}\text { Added } \\
(\%)\end{array}$ & Frequency & $\begin{array}{c}\text { Executed as } \\
\text { Pre-Planned } \\
(\%)\end{array}$ & $\begin{array}{c}\text { Modified } \\
(\%)\end{array}$ & $\begin{array}{c}\text { Added } \\
(\%)\end{array}$ \\
\hline $\begin{array}{l}\text { Activity type } \\
\text { Basic needs }\end{array}$ & 910 & 43.52 & 23.85 & 32.64 & 218 & 40.37 & 17.89 & 41.74 \\
Work/study & 780 & 39.87 & 27.95 & 32.18 & 155 & 50.97 & 18.06 & 30.97 \\
Shopping & 176 & 8.52 & 32.39 & 59.09 & 92 & 14.13 & 17.39 & 68.48 \\
Household & 365 & 42.74 & 18.63 & 38.63 & 106 & 37.74 & 16.98 & 45.28 \\
obligations & 293 & 16.72 & 28.67 & 54.61 & 138 & 23.19 & 15.94 & 60.87 \\
Leisure & 72 & 11.11 & 19.44 & 69.44 & 32 & 18.75 & 18.75 & 62.50 \\
Service & 354 & 18.36 & 24.29 & 57.34 & 73 & 13.70 & 13.70 & 72.60 \\
Social & 26 & 3.85 & 19.23 & 76.92 & 17 & 41.17 & 11.76 & 47.06 \\
\hline Other & 26 & & & & & & & \\
\hline
\end{tabular}
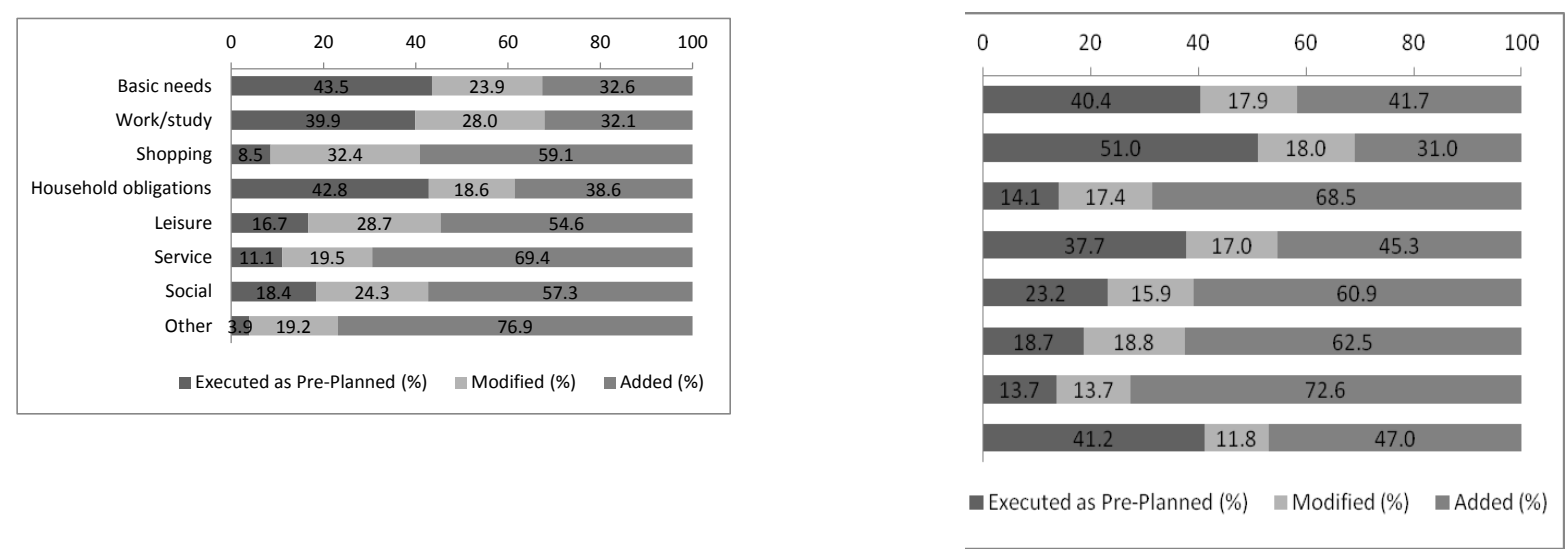


\section{Model estimation and results}

As Ferrer and Ruiz (in press) found, a significant correlation exists between the choices of pre-planning and rescheduling a car driving trips and those decisions should be modeled together (car driving trip scheduling model). Similarly, the decision to execute a walking trip as pre-planned in the agenda could also be correlated with the decision of pre-planning it or not. Therefore these decisions will be modeled together (walking trip scheduling model).

The statistical model used in this paper is derived from Heckman's (1979) work on selection bias in non-random samples. In our case, selection bias may arise because rescheduling decisions are only observed for those pre-planned trips, which is a restricted and non-random sample. As the two dependent variables of the analysis are dichotomous and may be correlated, the appropriate model is a bivariate probit model, and to take into account the possible selection bias, a bivariate probit model with sample selection was used. The estimator of this model was proposed by Van De Ven and Van Praag (1981) and is discussed in Greene (2000) and Liao (1995).

The models predict scheduling decisions related to car (car driving trip scheduling model) and walking trips (walking trip scheduling model) in two steps (pre-planned or unplanned; and for those pre-planned, rescheduled or not) as a function of demographic and socio-economic variables of the respondent, trip characteristics, characteristics of the activity at origin/destination and the scheduling decisions related to those activities.

Model Description: Bivariate probit model with sample selection

The dependent variables involved in the models are two, one for each step of the bivariate probit model with sample selection. For the first step of the model, the dependent variable $\left(y_{i 1}\right)$ is referred to the pre-planning of trips and takes the value of 1 if the executed trip is pre- 
planned and 0 if the trip is spontaneously executed. For the second step of the model, the dependent variable $\left(y_{i 2}\right)$ is related to the rescheduling of trips, and takes the value of 1 if the executed trip is executed as pre-planned and 0 otherwise.

Explanatory variables of the model are classified into four groups: individual and household characteristics, characteristics of the activity at origin and at destination, and trip attributes. A description of the explicative variables used is presented in Table 7 in the Appendix.

For a given individual $i, \mathrm{i}=1$ to $\mathrm{N}$, the specification of a bivariate probit model with sample selection is as follows (Greene 2000):

Prob $($ the executed trip is pre-planned $)=\operatorname{Pr}\left(y_{i 1}{ }^{*}>0\right)=\operatorname{Pr}\left(y_{i 1}=1\right)$

$$
\begin{aligned}
& y_{i 1}{ }^{*}=\beta_{1} x_{i 1}+\varepsilon_{i 1} \\
& y_{i 1}=1 \quad \text { if } y_{i 1}{ }^{*}>0 \quad \text { the trip is pre-planned in the agenda } \\
& y_{i 1}=0 \quad \text { if } y_{i 1}{ }^{*} \leq 0 \text { the trip is spontaneously executed }
\end{aligned}
$$

Prob (the trip is executed as pre-planned $)=\operatorname{Pr}\left(y_{i 2}{ }^{*}>0\right)=\operatorname{Pr}\left(y_{i 2}=1\right)$

$$
y_{i 2}^{*}=\beta_{2} x_{i 2}+\varepsilon_{i 2}
$$

$$
\begin{array}{lll}
y_{i 2}=1 & \text { if } y_{i 2}{ }^{*}>0 & \text { the trip is executed as pre-planned } \\
y_{i 2}=0 & \text { if } y_{i 2}{ }^{*} \leq 0 & \text { the trip is executed with modifications }
\end{array}
$$

where:

$\left(y_{i 2}, x_{i 2}\right)$ is observed only when $y_{i 1}=1$

And,

Prob is the normal distribution function,

$y_{i 1}{ }^{*}$ is the latent variable measuring the propensity of pre-planning a trip,

$y_{i 2}{ }^{*}$ is the latent variable measuring the propensity of executing a trip as pre-planned

$y_{i 1,} y_{i 2}$ are $y_{i 1}{ }^{*}, y_{i 2}{ }^{*}$ observed counterparts,

$\beta_{1}$ and $\beta_{2}$ are a set of parameters to be estimated,

$x_{i 1}, x_{i 2}$ are explanatory variables, 
$\varepsilon_{i 1,} \varepsilon_{i 2}$ are the error terms which have a bivariate normal distribution with $\mathrm{E}\left[\varepsilon_{i 1}\right]=\mathrm{E}\left[\varepsilon_{i 2}\right]=0, \operatorname{var}\left[\varepsilon_{i 1}\right]=\operatorname{Var}\left[\varepsilon_{i 2}\right]=1$ and $\operatorname{Cov}\left[\varepsilon_{i 1}\right]=\operatorname{Cov}\left[\varepsilon_{i 2}\right]=\rho$.

Both error terms $\varepsilon_{i 1}$ and $\varepsilon_{i 2}$ are correlated, $\rho$ is the correlation coefficient. If $\rho=0$, then there is no correlation between the errors and independent probit models are appropriate for the first and second step. However, if $\rho \neq 0$, then the bivariate probit is appropriate and parameter estimates in the outcome equation will be unbiased. The correlation between the error terms, $\rho$, has a potential range between -1 and 1 , and a correlation with an absolute value of 1 occurs if the coefficients of the two equations are estimated by identical processes, showing a potential selection bias.

To particularize the car driving scheduling model, we have:

$y_{i 1}=1$ if the car driving trip is pre-planned in the agenda, $y_{i 1}=0$ otherwise

$y_{i 2}=1$ if the car driving trip is executed exactly as pre-planned in the agenda, $y_{i 2}=0$ otherwise And for the walking trip scheduling model:

$y_{i 1}=1$ if the walking trip is pre-planned in the agenda, $y_{i 1}=0$ otherwise $y_{i 2}=1$ if the walking trip is executed exactly as pre-planned in the agenda, $y_{i 2}=0$ otherwise.

Random parameters are used in first and second steps of the models. The underlying motivation of the random parameters is to accommodate individual heterogeneity in the parameters of the models. The general form of a random parameter is:

$$
\beta_{i}=\beta^{0}+\sigma v_{i}
$$

where $\beta^{0}$ is the mean of the parameter, which is fixed and common to all respondents, while $\sigma$ is the standard deviation of the parameter and $v_{i}$ a normally distributed term. Note that nonrandom parameters have $\sigma=0$, so their formulation is $\beta_{i}=\beta^{0}$.

The models are estimated by maximum likelihood, where the log likelihood is:

$\sum_{y_{i 1}=1, y_{i 2}=1} \log \Phi_{2}\left\lfloor\beta_{1}^{\prime} \cdot x_{i 1}, \beta_{2}^{\prime} \cdot x_{i 2}, \rho\right\rfloor+\sum_{y_{i 1}=1, y_{i 2}=0} \log \Phi_{2}\left\lfloor\beta_{1}^{\prime} \cdot x_{i 1},-\beta_{2}^{\prime} \cdot x_{i 2},-\rho\right\rfloor-\sum_{y_{i 1}=0} \log \Phi\left[-\beta_{1}^{\prime} \cdot x_{i 1}\right\rfloor$ 
Where $\Phi_{2}$ is a bivariate normal cumulative distribution function and $\Phi$ is a univariate cumulative distribution function.

Equation (1) is to be maximized with respect to the parameters $\beta_{1}^{\prime}, \beta_{2}^{\prime}$ and $\rho$.

Empirical results

The models were estimated using Nlogit 5 software by the maximum likelihood method. The critical level of significance chosen was 0.10 and statistically insignificant variables are excluded from the model. However, some variables not significant at 0.10 level are kept in the models to understand the direction of their effects.

Results given by the bivariate probit model with sample selection for the scheduling and rescheduling of car driving trips and walking trips are summarized in Table 5 and 6.

As can be seen, the $\rho$ coefficients in Table 5 are significantly different from zero (0.494 for the car driving trips scheduling model; -0.525 for the walking trips scheduling model), validating the methodological approach used in this study. Thus, the bivariate probit models with sample selection are appropriate to avoid the biased estimation of the coefficients and marginal effects that might result if independent probits were implemented for the second step of the models. The negative sign of the $\rho$ coefficients suggest that unobserved factors that increase the probability of pre-planning a trip also decrease the propensity to execute the travel episode as pre-planned.

The goodness of fit of the models is measured by the McFadden Pseudo R-squared statistic, which is 1 minus the ratio of the log-likelihood value of the full model and the loglikelihood value of the restricted model (constant only model). A McFadden Pseudo Rsquared value closer to 1 represents better fit to the observed data. In our case, the relatively high values of the McFadden Pseudo R-squared for both models indicate a substantial increase in the log likelihood function due to the inclusion of the explanatory variables in the models. 
Table 5 Coefficients of the Bivariate Probit Models with Sample Selection: Car Driving Trips Model and Walking Trips Model[TRS1]

\begin{tabular}{|c|c|c|c|c|}
\hline \multirow[b]{2}{*}{ Variables } & \multicolumn{2}{|c|}{ Car driving trips model } & \multicolumn{2}{|c|}{ Walking trips model } \\
\hline & $\begin{array}{c}\text { First step } \\
\text { coefficient } \\
(\mathrm{y} 1)\end{array}$ & $\begin{array}{c}\text { Second step } \\
\text { coefficient } \\
\text { (y2) }\end{array}$ & $\begin{array}{c}\text { First step } \\
\text { coefficient } \\
(\mathrm{y} 1)\end{array}$ & $\begin{array}{c}\text { Second step } \\
\text { coefficient } \\
\text { (y2) }\end{array}$ \\
\hline Constant & $-0.551^{\star \star \star}$ & $-1.239^{\star \star \star}$ & $-0.379^{* *}$ & $1.152^{\star \star \star}$ \\
\hline \multicolumn{5}{|c|}{ Type of scheduling of the activity at origin (A1) and destination (A2) } \\
\hline A1 $=$ spontaneously added & -0.195 & $-1.207^{* * *}$ & $-0.777^{\star \star \star}$ & - \\
\hline A2 $=$ spontaneously added & $-0.896^{\star * *}$ & $-0.581^{* * *}$ & $-0.976^{* * *}$ & - \\
\hline$A 1=$ pre-planned & $1.001^{* \star *}$ & - & $0.778^{\star \star \star}$ & - \\
\hline $\mathrm{A} 2=$ pre-planned & $0.921^{\star \star \star}$ & - & $0.976^{\star \star \star}$ & - \\
\hline $\mathrm{A} 1=$ exec. as pre-planned & - & - & - & $0.603^{\star \star *}$ \\
\hline $\mathrm{A} 1 \& \mathrm{~A} 2=$ modified & & $-1.870^{\star \star \star}$ & - & $-1.329^{\star \star \star}$ \\
\hline $\begin{array}{l}\text { A1 }=\text { exec. as pre-planned \& } \\
\text { A2 }=\text { Modified } \\
\text { A1 }=\text { Modified \& } \\
\text { A2 }=\text { executed as pre-planned }\end{array}$ & & $\begin{array}{l}-0.493^{\star * *} \\
-0.382^{\star * *}\end{array}$ & - & $\begin{array}{l}-0.892^{\star \star \star} \\
-0.604^{\star \star \star}\end{array}$ \\
\hline \multicolumn{5}{|l|}{ Activity at origin of the trip (A1) } \\
\hline Housework & - & $0.322^{\star * *}$ & - & - \\
\hline \multicolumn{5}{|l|}{ Trip characteristics } \\
\hline Trip start time & - & $-0.126^{* * *}$ & - & - \\
\hline Trip companions ( $1=y e s, 0=$ no) & - & - & - & $-0.449^{\star * *}$ \\
\hline Trip duration > $20 \mathrm{~min}$ & - & $-0.119^{*}$ & - & $-0.629^{\star \star *}$ \\
\hline From work to home & $0.685^{\star \star *}$ & & $0.973^{* * *}$ & - \\
\hline From home to work & $0.846^{* \star *}$ & & - & $1.151^{\star \star *}$ \\
\hline From work to other & - & $0.505^{\star \star *}$ & - & $1.125^{* *}$ \\
\hline From home to other & - & $0.216^{\star *}$ & - & $0.494^{\star \star \star}$ \\
\hline \multicolumn{5}{|c|}{ Activity at destination of the trip (A2) } \\
\hline Sunday & - & $-0.490^{\star * \star}$ & - & - \\
\hline Day (0:Mond.,6:Sund.) & - & - & - & $-0.084^{*}$ \\
\hline Work/study & $0.263^{* *}$ & $0.285^{\star *}$ & $0.594^{\star * *}$ & - \\
\hline Household obligations & $0.649^{* \star *}$ & - & & \\
\hline Housework*gender & - & - & $0.818^{\star * *}$ & - \\
\hline Leisure & $0.568^{\star \star *}$ & - & $0.471^{* *}$ & - \\
\hline \multicolumn{5}{|c|}{ Individual and household characteristics } \\
\hline $31-50$ years & - & - & - & $0.522^{\star \star \star}$ \\
\hline$>50$ years & - & - & - & $0.691^{* *}$ \\
\hline 2 members in $\mathrm{HH}$ & - & - & $-0.509^{* *}$ & - \\
\hline Number of cars & $-0.102^{* * *}$ & - & -0.093 & - \\
\hline Education Level & - & $-0.066^{* * *}$ & - & $-0.140^{\star * *}$ \\
\hline$\rho$ (rho) & $-0.494^{\star \star \star}$ & -4.24 (t-value) & $-0.525^{\star \star \star}$ & -2.98 (t-value) \\
\hline Log-likelihood & -1972.931 & & -459.021 & \\
\hline Restricted Log-likelihood & -3211.233 & & -842.383 & \\
\hline McFadden Pseudo R-squared & 0.386 & & 0.455 & \\
\hline
\end{tabular}

Note: ${ }^{* * *},{ }^{* *},{ }^{*}$ significance at $1 \%, 5 \%, 10 \%$ level 
Table 6 Marginal Effects of the Bivariate Probit Models with Sample Selection: Car Driving Trips Model and Walking Trips Model

\begin{tabular}{|c|c|c|c|c|c|c|c|c|}
\hline \multirow{3}{*}{ Variables } & \multicolumn{4}{|c|}{ Car driving trips model } & \multicolumn{4}{|c|}{ Walking trips model } \\
\hline & \multicolumn{2}{|c|}{$\frac{\partial \operatorname{Prob}(y 1)}{\partial x_{1}}$} & \multicolumn{2}{|c|}{$\frac{\partial \operatorname{Prob}(y 2 \mid y 1=1)}{\partial x_{i}}$} & \multicolumn{2}{|c|}{$\frac{\partial \operatorname{Prob}(y 1)}{\partial x_{1}}$} & \multicolumn{2}{|c|}{$\frac{\partial \operatorname{Prob}(y 2 \mid y 1=1)}{\partial x_{i}}$} \\
\hline & $\begin{array}{c}\text { Marginal } \\
\text { effect }\end{array}$ & t-value & $\begin{array}{c}\text { Marginal } \\
\text { effect }\end{array}$ & t-value & $\begin{array}{c}\text { Marginal } \\
\text { effect }\end{array}$ & t-value & $\begin{array}{c}\text { Marginal } \\
\text { effect }\end{array}$ & $\mathrm{t}$-value \\
\hline \multicolumn{9}{|c|}{ Type of scheduling of the activity at origin (A1) and destination (A2) } \\
\hline$A 1=$ spon. added & -0.052 & -1.89 & -0.537 & -11.28 & -0.140 & -13.66 & -0.104 & -2.39 \\
\hline$A 2=$ spon. added & -0.244 & -7.77 & -0.351 & -7.64 & -0.188 & -24.37 & -0.129 & -2.48 \\
\hline A1 $=$ pre-planned & 0.234 & 7.50 & 0.115 & 3.38 & 0.140 & 13.67 & 0.104 & 2.40 \\
\hline A2 $=$ pre-planned & 0.231 & 7.62 & 0.106 & 3.43 & 0.188 & 24.44 & 0.129 & 2.48 \\
\hline $\begin{array}{l}\mathrm{A} 1=\text { exec. as pre- } \\
\text { planned }\end{array}$ & - & - & - & - & - & - & 0.244 & 4.70 \\
\hline A1 \& $A 2=$ modified & - & - & -0.797 & -16.25 & - & - & -0.537 & -5.03 \\
\hline $\begin{array}{l}\text { A1 = exec. as pre- } \\
\text { planned \& } \\
\text { A2 = Modified } \\
\text { A1 = Modified \& }\end{array}$ & - & - & -0.209 & -4.37 & - & - & -0.360 & -3.43 \\
\hline $\begin{array}{l}\mathrm{A} 2=\text { executed as } \\
\text { pre-planned }\end{array}$ & - & - & -0.163 & -3.17 & - & - & -0.244 & -4.70 \\
\hline \multicolumn{9}{|c|}{ Activity at origin of the trip (A1) } \\
\hline Househ. obligations & - & - & 0.137 & 3.03 & - & - & - & - \\
\hline \multicolumn{9}{|l|}{ Trip characteristics } \\
\hline Trip start time & - & - & -0.054 & -3.13 & - & - & - & - \\
\hline $\begin{array}{l}\text { Trip companions } \\
(1=y e s, 0=\text { no })\end{array}$ & - & - & - & - & - & - & -0.182 & -2.76 \\
\hline $\begin{array}{l}\text { Trip duration } \\
>20 \mathrm{~min}\end{array}$ & - & & -0.051 & -1.73 & - & - & -0.254 & -2.69 \\
\hline From work to home & 0.140 & 5.30 & 0.079 & 3.07 & 0.191 & 2.19 & 0.132 & -1.76 \\
\hline From home to work & 0.166 & 4.91 & 0.097 & 2.95 & - & - & 0.465 & 3.15 \\
\hline From work to other & - & - & 0.215 & 3.30 & - & - & 0.455 & 2.51 \\
\hline From home to other & - & - & 0.092 & 2.19 & - & - & 0.199 & 2.71 \\
\hline \multicolumn{9}{|c|}{ Activity at destination of the trip (A2) } \\
\hline Sunday & - & - & -0.209 & -3.09 & - & - & - & - \\
\hline Day (0: Mon.,6: Sun.) & - & - & - & - & - & - & -0.034 & -1.98 \\
\hline Work/study & 0.057 & 3.05 & 0.152 & 4.21 & 0.121 & 3.45 & 0.079 & 1.92 \\
\hline Housework & 0.132 & 7.29 & 0.075 & 3.41 & - & - & - & - \\
\hline Housework ${ }^{*}$ gender & - & - & - & - & 0.151 & 3.02 & 0.109 & 1.95 \\
\hline Leisure & 0.113 & 6.66 & 0.065 & 3.24 & 0.095 & 2.92 & 0.063 & 1.79 \\
\hline \multicolumn{9}{|c|}{ Individual and household characteristics } \\
\hline $31-50$ years & - & - & - & - & - & - & 0.211 & 3.14 \\
\hline$>50$ years & - & - & - & - & - & - & 0.279 & 2.37 \\
\hline 2 members in $\mathrm{HH}$ & - & - & - & - & -0.091 & -2.70 & -0.068 & -1.55 \\
\hline Number of cars & -0.023 & -3.58 & -0.012 & -2.64 & -0.019 & -1.46 & -0.012 & -1.19 \\
\hline Education Level & - & - & -0.028 & -3.43 & - & - & -0.057 & -2.85 \\
\hline
\end{tabular}


First step: to pre-plan or spontaneously execute a trip

The probit for the first step of the bivariate models analyzes the decision to pre-plan or to spontaneously execute a trip without any pre-planning. Marginal effects are calculated using univariate probit models and evaluated at the mean of the explanatory variables. Positive signs of the marginal effects are associated to a higher probability that the executed travel episode is pre-planned. Next, results for the first step of the models are discussed by type of explanatory variable.

Type of scheduling of the activity at origin and destination

As expected, the estimated marginal effects suggest that the scheduling process of car driving and walking trips is highly influenced by the type of scheduling of the activity at origin and destination of the trip. If the activity at origin or destination is spontaneously added, the likelihood of pre-planning the trip decreases. Similarly, if there is a pre-planning of the activities at origin or destination, trips are normally pre-planned. Marginal effect values are in general of similar magnitude in both models, which indicates that the type of scheduling of both previous and posterior activities influence in the same way the decision to pre-plan or not a car driving or a walking trip.

Characteristics of the activity at origin (No hay variables significativas, podemos decir algo, $u$ omitirlo directamente) LOOMITIMOS DIRECTAMENTE

\section{Trip characteristics}

Marginal effects indicate that trips from work to home are more often pre-planned: $14.0 \%$ more likely for car driving trips, and $19.1 \%$ for walking trips. In the case of car trips from home to work, the likelihood of pre-planning increases by $16.6 \%$. These results are consistent with previous results finding that pre-planned activities at origin or destination 
increase the probability of pre-planning the trip, and in this case, work-related activities are mandatory and generally pre-planned.

\section{Characteristics of the activity at destination}

Some activity types at destination increase the propensity to pre-plan a car driving trip: work or study-related trips (by 5.7\%), household obligations (by $13.2 \%$ ) and leisure (by $11.3 \%$ ). In the case of walking trips, similar results are found: executing a walking trip for work or studyrelated purposes increases the probability of pre-planning the trip by $12.1 \%$, household obligations executed by women (by $15.1 \%$ ) and leisure (by $9.5 \%$ ).

\section{Household and individual characteristics}

Walking trips are more spontaneously added by individuals with for families withof two members. This result indicates that those living alone or in households with more than two family members (e.g. households with children) have less flexible agendas, increasing the pre-planning of walking trips.

Modeling results show that the number of cars in the household also explains the preplanning of car trips: each additional car in the household increases by $2.3 \%$ the probability of spontaneously adding car driving trips. Our explanation is that the higher number of cars in the household allow for a more spontaneous scheduling behavior. This result is contrary to findings by Mohammadian and Doherty (2006), who found that those with a greater number of cars within the household tend to plan more in advance, however, their results may differ from our findings because their analysis did not include activities planned the same day or impulsively added just before execution. The effect of the number of cars in the household is also found significant at the 0.15 level for the scheduling of walking trips: each additional car within the family increases by $1.9 \%$ the likelihood of spontaneously adding walking trips.

Second step: to execute as pre-planned or modify a trip 
The second step of the bivariate model analyzes the decision to execute a car driving or walking trip as planned or modifying any of the pre-planned attributes of the pre-planned-trip. The significant and different zero values of $\rho$ confirm the bivariate probit models with sample selection are appropriate and also certify that the parameter estimates of the second steps are unbiased. The bias in the estimated coefficients could lead to erroneous conclusions, or even, contradictory results. As the correlation between the error terms in the two models is negative $(\rho<0)$, it implies that if a person has a high (low) value in the distribution of unobserved effects in the first equation, he or she is likely to have a low (high) value in the distribution of unobserved effects in the second equation. These results prove that rescheduling and scheduling decisions are correlated, and have to be simultaneously analyzed, involving some of the previous research in this field. For example, Van Bladel et al. (2009) separately analyzed whether planned activities are executed with or without modifications in any of their attributes and the factors influencing these rescheduling decisions using mixed logit models.

For this second step of the models, marginal effects are evaluated at the mean of the explanatory variables using results provided by the bivariate probit models. Positive signs of the explanatory variables and marginal effects are associated with a higher probability that the travel episode is executed exactly as pre-planned.

\section{Type of scheduling of the activity at origin and destination}

Similarly to results provided by the first step of the model, marginal effects suggest that the scheduling process of car driving and walking trips is highly influenced by the type of scheduling of the activity at origin and destination of the trip.

A highly significant result shows that when both the activity at origin and at destination of the trip are modified, the likelihood of modifying the car driving trip substantially increases: $79.7 \%$ for car driving trips and $5 \underline{34} . \underline{7}+\%$ for walking trips. If the anterior or posterior activity is spontaneously added, again both car driving and walking trips tend to be modified prior to 
$\underline{\text { their execution. But in this later case, marginal effects associated to car driving trips are }}$ much higher $(-0.537$ and -0.351$)$ than walking trips $(-0.104$ and -0.129$)$. The lower value for walking trips explains that once pre-planned, these trips are relatively less likely to be modified than car driving trips, showing a less flexible rescheduling behavior. The explanation of this difference between car driving and walking trips may be related to the fact that the data used in our study was provided by sample of the study, habitual car users. This population is characterized by often pre-planning and executing car driving trips, and if they pre-plan a walking trip it may be because they are certain that they will execute it exactly as planned.

For both car driving and walking trips, when the activity at origin is executed as preplanned and the activity at destination is modified, trips are more likely to be modified. The probability of modifying the trip is lower for trips with inverse scheduling decisions for the activity at origin and destination, indicating a more important influence of changes in the activity at destination on the rescheduling of trips.

\section{Characteristics of the activity at origin}

Only the activity at origin related to household obligations is significant to explain the rescheduling of car trips, with an expected sign.

\section{A household obligation at the origin of the trip increases by $13.7 \%$ the likelihood of executing}

a car driving trip as pre-planned. Obliged activities are usually more rigid than others, which influences the subsequent trip to be less flexible. This also occurs when the obliged activity is at destination of the trip (see below).

\section{Trip characteristics}

The later the start of the car trip starts, the more tendency-likely it is to modify the preplanned trip[TRS2]. Joh et al. (2005) and Van Bladel et al. (2009) also found that pre-planned activities to be executed later during the day tend to be more rescheduled than those pre- 
planned earlier in the day. On the other hand, trip timing does not significantly influence the flexibility of walking trips.

An interesting explicative variable is related to the duration of the trip: car driving and walking trips longer than 20 minutes are modified. This is because the longer the activity, the more likely it is to interfere with other activities in the agenda. This result is consistent with Nijland et al. (2009), i.e. that longer travel times increase the probability of cancelling an activity. Marginal effects indicate that walking trips are more sensitive to changes when longer travel times are pre-planned. The explanation of this finding may also be related to the higher proportion of walking trips longer than 20 minutes pre-planned by students, and the fact that young people show a more spontaneous rescheduling behavior.

The odds of rescheduling of $-\mathrm{a}$ walking trip increase by $18.2 \%$ if there are trip companions. If the trip is performed with companions, it becomes less controllable: modifications in the schedules of any of the people involved in the trip can affect the common plan. But trip companions does not significantly influence the rescheduling of a walking trip, which suggests that companions have to adapt their trips characteristics to driver's travelling plan.

The marginal effects of the variables related to the location of the origin and destination of the trips like "work to home", "home to work", "work to other" and "home to other" confirm the following result: walking trips, once pre-planned, are less modified, showing a more rigid rescheduling behavior compared to car driving trips. Most important differences are found for trips from "home to work" and "work to other", cases in which marginal effects for the walking model are substantially higher than marginal effects in the car driving model. In particular, estimated marginal effect of "home-to-work" on walking trips is much higher (0.465) than on car driving trips (0.097). This result may be explained by the fact that walking trips are shorter than driving trips, being easier to be executed as pre-planned even though anterior and/or posterior activities are modified. 


\section{Characteristics of the activity at destination}

The day of execution of the trip has a similar influence on the scheduling decisions related to car driving and walking trips: trips linked to activities to be performed on Sunday are the most modified[TRS3]. This is a logical results, considering that during weekend people usually have less pressure to perform activities and travels as they were pre-planned. Car driving and walking trips to work/study or to undertake leisure activities are normally executed as preplanned. In the case of trips to work/study, the result is explained by the fact that these trips are to undertake mandatory activities with fixed starting and ending times. Other results suggest that car driving trips to execute household obligations are executed without changes; and also, female walking trips for the same purposes.

Household obligations at destination have a significant and positive marginal effect on the probability of modifying a pre-planned car driving trip. Although marginal effect value is low (0.075), meaning a slight tendency towards executing trips as pre-planned. Similarly, household obligations at destination affects in the same way on walking trips made by females. As mentioned earlier, obliged activities are usually more rigid than other, influencing related trips to be less flexible.

\section{Household and individual characteristics}

Age is a significant factor for to explain rescheduling walking trips. People over 30 are moreincrease the likelihoody to execute their pre-planned walking trips without changes by at least $21.1 \%$. This is an important finding, as it suggests that activity-travel planning issues are different according to age. This result may be explained due to the more spontaneous behavior of younger people, with less tight schedules than those older. On the other hand, age does not significantly affects the probability of modifying a car driving trip.

Estimated marginal effects of education level on the probability of modifying a preplanned trip are significant and negative in both models, although with a low value $(-0.028$ 
and -0.057). Therefore, tThe higher the education level of the respondent the more probability to modify pre-planned car or walking trips. Van Bladel et al. (2009) also found that those with secondary, pre-university or a university degree have a higher tendency to reschedule their activities and trips. Similarly, results by Joh et al. (2005) showed that the probability of modifying an activity or travel episode increases in parallel with income.

Individuals in two-members fFamilies with two members within the household-increase the probability to modify their pre-planned walking trips by $6.8 \%$, despite this variable is only significant at the 0.15 level. This result is in line with that found in the first step of the model showing that those living alone or in households with more than two family members (e.g. households with children) have less flexible agendas, increasing the pre-planning and execution of walking trips as pre-planned. Joh et al. (2005) found that modifying a travel or activity episode is more likely when the household size is small.

Estimated marginal effects of number of cars on the probability of modifying a pre-planned $\underline{\text { trip are significant and negative in both models, although with a low value as well }(-0.012) \text {. As }}$ the number of cars in the household increase, so does the probability of modifying the preplanned trip. Household motorization positively influences the flexibility of scheduling decisions.

\section{Conclusions}

To the best of our knowledge, this study is the first which that explores the differences and similarities of rescheduling decisions between car driving trips and walking trips in $\underline{\text { by habitual }}$ car drivers'scheduling and rescheduling decisions between car driving trips and walking trips. The study was carried out using an activity-travel scheduling data set collected in Valencia (Spain) in 2010. Two bBivariate probit models with sample selection are used to accommodate the influence of pre-planning on the decision to execute a trip as pre-planned or not. Two models are developed:: one model for car driving trips and another model for 
walking trips. Factors considered are not only household, individual characteristics, and trip facets, but also characteristics of the activity at origin and at destination along with the type of scheduling decisions.

Whether referring to car driving or walking trips, $t$ The results of the models reveal that a significant correlation exists between the choices of pre-planning and rescheduling for both types of trips. This result-finding proves that the study of rescheduling decisions has to be analyzed together with scheduling-pre-planning decisions and involves some of the previous research in this field.

Pre-planning trip decisions are much related to scheduling decisions of the anterior or posterior activity. Trips related to work/study and household activities are more probably preplanned. The number of cars in the household increase the probability of spontaneously add $\underline{\text { trips, so pre-planning trips is more flexible. Similar marginal effects are estimated for both car }}$ driving and walking trips in all cases.

Considering the magnitude of the estimated marginal effects, the scheduling decisions associated to the anterior and/or posterior activities are the most important explicative factors of the trip rescheduling decisions. This is an expected result. But it is important to note here the first difference between car driving and walking trips: if the anterior or posterior activity is spontaneously added, the probability of modifying a pre-planned car driving trip is much higher than a walking trip.

Some-Other differences and similarities-between the scheduling decisions related to car driving and walking trips arise in the models. One of the main differences is that Homework walking trips, once pre-planned, are usually executed without changes, whereashave a much higher probability of being executed as pre-planned than car driving trips-show a more flexible rescheduling behavior. The duration of the trip also provides a relevant difference: trips longer than 20 minutes are often-more likely to be modified; however, walking trips of this type tend to be more frequently-rescheduled than car driving trips.

$\underline{\text { Individual and household characteristics play a more important role in explaining }}$ walking than car driving scheduling decisions. People over 30 more often execute their 
walking trips as pre-planned. Furthermore, the number of family members in the household is indicative of the pre-planning and rescheduling behavior: families with two members spontaneously add and modify more walking trips than other families. On the other hand, age and household size are not significant factors in explaining car driving scheduling decisions.

Similarities between both models reveal that significant variation in the rescheduling behavior happens throughout the week. The ending of the week (Sunday) is the moment with more probability to modify pre-planned trips, whether they are car driving or walking trips. In addition, one interesting finding suggests that modifications in the activity pre-planned at destination are more influential than modifications in the activity pre-planned at origin on the likelihood of modifying attributes of the car driving or walking trip.

The walking scheduling decision model also provides very interesting results. People over 30 more often execute their walking trips without changes. Furthermore, the number of family members in the household is indicative of the pre-planning and rescheduling behavior: families with two members spontaneously add and modify more walking trips than other families.

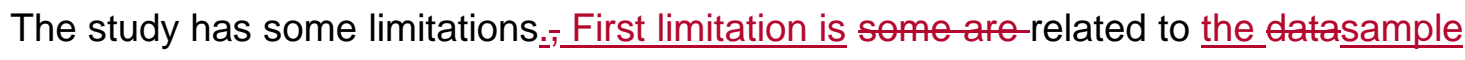
size-sampling: it is relatively small and only refers to habitual car users. Another limitation affects the scheduling time horizon of activities and trips: most of the modifications of preplanned activities are carried out in different time horizons but this information were not considered in the analysis. With the aim to simplify the analysis, deleted-pre-planned and not executed (deleted) trips-and activities were excluded. Nevertheless, this study offers indications to improve the current generation of activity-travel scheduling models. For example, there is some heterogeneity in the decision processes depending on the travel mode used. Thus, a higher disaggregation of the scheduling decisions according to the travel mode seems necessary in the current generation of activity scheduling and rescheduling models.

Further research is needed to better understand the scheduling process decisions associated with activities and trips. This will involve not only considering those pre-planned 
and deleted trips but also analyzing the qualitative data available to understand the results provided by some variables. Furthermore, the comparison of the activity scheduling process between habitual car drivers and sustainable transportation users will provide insights to more effective transportation policies.

\section{Acknowledgements}

We would like to thank the Spanish Ministry of Science and Innovation for funding the research project PEATONTRA2011-27415.

\section{References}

Arentze, T. and Timmemans, H. ALBATROSS - A Learning Based Transportation Oriented Simulation System. European Institute of Retailing and Services Studies (EIRASS), Technical University of Eindhoven (2000).

Asadi-Shekari, Z., Moeinaddini, M., Zaly Shah, M. Non-motorized level of service: addressing challenges in pedestrian and bicycle level of service. Transport Reviews 33 (2), pp. 166-194 (2013)

Auld, J. and Mohammadian, A. Activity planning processes in the Agent-based Dynamic Activity Planning and Travel Scheduling (ADAPTS) model. Transportation Research Part A: Policy and Practice 46 (8), pp.1386-1403 (2012)

Bassett, D., Pucher, J., Buehler, R., Thompson, D., Crouter, S. Walking, cycling, and obesity rates in Europe, North America, and Australia. Journal of Physical Activity \& Health 5, pp. 795-814 (2008)

Borst, H.C., S.I. de Vries, Graham, J.M.A., van Dongen, J.E.F., Bakker, I., Miedema, H.M.E. Influence of environmental street characteristics on walking route choice of elderly people, Journal of Environmental Psychology 29, 477-484. (2009)

Canca, D., Zarzo, A., Algaba, E., Barrena, E. Macroscopic attraction-based simulation of pedestrian mobility: A dynamic individual route-choice approach. European Journal of Operational Research 231, Issue 2, p. 428-442 (2013)

Cao, X., Handy, S.L., Mokhtarian, P.L. The Influences of the Built Environment and Residential Self-Selection on Pedestrian Behavior: Evidence from Austin, TX, Transportation 33, Issue 1, pp 1-20 (2006)

Cervero R. and Duncan M. Walking, bicycling, and urban landscapes: evidence from San Francisco Bay Area. American Journal of Public Health 93:(9), 1478-1483 (2003)

Clark, A.F. and Doherty, S.T. Examining the nature and extent of the activity-travel preplanning decision process. Proceedings of the 87th Annual Meeting of the Transportation Research Board, Washington D.C., (2008) 
Doherty, S.T. An activity scheduling process approach to understanding travel behavior. The 79th Annual Meeting of the Transportation Research Board, Washington D.C., January 9-13, (2000)

Doherty, S.T., and Miller, E.J. A computerized household activity scheduling survey, Transportation 27, pp.75-97. (2000)

Doherty, S.T. How far in advance are activities planned? Measurement challenges and analysis. The $84^{\text {th }}$ Anuual Meeting of the Transportation Research Board, Washington D.C. (2005)

European Commission - EC. White Paper. Roadmap to a Single European Transport Area- Towards a competitive and resource efficient transport system [COM(2011)144]. Publications Office of the European Union, Luxembourg (2011)

Ferrer, S. and Ruiz, T. Factors Influencing the Travel Scheduling of Driving Trips in Habitual Car Users. Transportation Research Record: Journal of the Transportation Research Board, Washington D.C., 2014. (in press)

García-Garcés, P. and Ruiz, T. Simultaneous Analysis of Global Decisions in the Activity-Travel Scheduling Process. Transportation Research Record: Journal of the Transportation Research Board 2382 , Washington D.C., pp. 121-131 (2013)

Golledge, R.G., Kwan, M.-P., and Garling, T. Computational-process modelling of household travel decisions using a geographical information system. Working Paper, UCTC No. 218, The University of California Transportation Center, University of California at Berkeley (1994)

Greene, W. Econometric Analysis, Fourth Edition. 2000, New York: Prentice Hall.

Greenwald, M. and Boarnet, M.G. The built environment as a determinant of walking behavior: analyzing nonwork pedestrian travel in Portland, Oregon. Transportation Research Record: Journal of the Transportation Research Board 1780, pp. 33-42 (2002)

Guinn, J. M. and Stangl, P. Pedestrian and bicyclist motivation: an assessment of influences on pedestrians' and bicyclists' mode choice in Mt. Pleasant, Vancouver, Urban, Planning and Transport Research: An Open Access Journal 2, Issue 1, pp. 105-125 (2014)

Habib, K. A. random utility maximization (RUM) based dynamic activity scheduling model: application in weekend activity scheduling. Transportation 38, pp.123-151 (2011)

Habib, K., Morency, C., and Trépanier, M. Integrating parking behaviour in activity-based travel demand modelling: Investigation of the relationship between parking type choice and activity scheduling process, Transportation Research Part A 46, pp. 154-166 (2012)

Heckman, James J. Sample Selection Bias as a Specification Error, Econometrics 47 (1), pp.-153-161 (1979)

Kelly, C.E.,Tight, M.R., Hodgson, F.C., Page, M.W. A comparison of three methods for assessing the walkability of the pedestrian environment, Journal of Transport Geography 19, Issue 6, pp.1500-1508, Special section on Alternative Travel futures (2011) 
Joh, C.-H., Doherty, S.T., and Polak, J.W. Analysis of factors affecting the frequency and type of activity schedule modification. Transportation Research Record: Journal of the Transportation Research Board 1926, Washington D.C., pp. 19-25. (2005)

Lachapelle, U. and Noland, R.B. Does the commute mode affect the frequency of walking behavior? The public transit link. Transport Policy 21, pp.26-36 (2012)

Liao, T.F. The Nonrandom Selection of Don't Knows in Binary and Ordinal Responses: Corrections with the Bivariate Probit Model with Sample Selection, Quality and Quantity 29, pp. 87-110 (1995)

Liao, F., Arentze, T., and Timmermans, H. Incorporating space-time constraints and activity-travel time profiles in a multi-state supernetwork approach to individual activity-travel scheduling. Transportation Research Part B 55, pp.41-58 (2013)

Marcum, C.S. Age Differences in Daily Social Activities, Research on Aging 35(5), pp.612-640 (2013)

Mohammadian, A. and Doherty, S.T. Modeling activity scheduling time horizon: duration of time between planning and execution of pre-planned activities. Transportation Research Part A 40 (6), pp.475-490 (2006)

Monzón, A., Cascajo, R., Alonso, A. Observatorio de la Movilidad Metropolitana: informe 2011. Ministerio de Agricultura, Alimentación y Medio Ambiente. Madrid (2007)

Nijland, E.W.L., Arentze, T.A., Borgers, A.W.J., Timmermans, H.J.P. Individuals' activity-travel rescheduling behaviour: experiment and model-based analysis. Environment and Planning A 41(6), pp.1511-1522 (2009)

Recker, W.W., McNally, M.G.,Root, G.S. A model of complex travel behaviour: Part I -theoretical development. Transportation Research A 20a, pp.307-318 (1986)

Roorda, M.J., Doherty, S.T., and Miller, E.J. Operationalising household activity scheduling models: addressing assumptions and the use of new sources of behavioral data. In: Lee-Gosselin, M., Doherty, S.T. (Eds.), Integrated Land-use and Transportation Models: Behavioural Foundations. Elsevier, Oxford, pp.61-85 (2005)

Ruiz, T. and Timmermans, H.J.P. Changing the timing of activities in resolving scheduling conflicts. Transportation 33, 5, pp. 429-445 (2006)

Ruiz, T. and Roorda, M.J. Analysis of planning decisions during the activity scheduling process. Transportation Research Record: Journal of the Transportation Research Board 2054, Washington D.C., pp. 46-55 (2008)

Ruiz, T. and M.J. Roorda. Assessing planning decisions by activity type during the scheduling process. Transportmetrica 7, 6, , pp. 417-442 (2011)

Ruiz, T., García-Garcés, P., Ferrer, S. Measuring the impact of travel behavior change programs on the activitytravel scheduling process. Presented at the 13th International Conference on Travel Behavior Research, Toronto (2012) 
Sehatzadeh, B., Noland, R.B., Weiner, M.D. Walking frequency, cars, dogs, and the built environment. Transportation Research Part A: Policy and Practice 45, Issue 8, p. 741-754 (2011)

Van Bladel, K., Bellemans, T., Janssens, D., Wets, G. Activity travel planning and rescheduling behavior: Empirical analysis of influencing factors. Transportation Research Record: Journal of the Transportation Research Board 2134, Washington D.C., pp. 135-142 (2009)

Van den Berg, P., Arentze, T., Timmermans, H.J.P. Factors influencing the planning of social activities. Transportation Research Record: Journal of the Transportation Research Board 2157, Washington D.C., pp.63-70 (2010)

Van de Ven, W.P.M.M. and Van Praag, B.M.S. The Demand for Deductibles in Private Health Insurance: A Probit Model with Sample Selection, Journal of Econometrics 17, pp. 229-252 (1981)

Weinstein, A., Schlossberg, M., Irvin, K. How Far, by Which Route and Why? A Spatial Analysis of Pedestrian Preference, Journal of Urban Design 13:1, 81-98. (2008)

Yin, L. Assessing Walkability in the City of Buffalo: Application of Agent-Based Simulation. Journal of Urban Planning and Development 139(3), 166-175 (2013)

Xiao, F., and Lam, W.H.K. A network equilibrium approach for modelling activity travel pattern scheduling problems in multi-modal transit networks with uncertainty. Transportation 41, pp.37-55 (2014)

Zhan, G. Does the pedestrian environment affect the utility of walking? A case of path choice in downtown Boston, Transportation Research Part D: Transport and Environment 14, Issue 5, p. 343-352 (2009)

Zielstra, D. and Hartwig, H.H. Using Free and Proprietary Data to Compare Shortest-Path Lengths for Effective Pedestrian Routing in Street Networks, Transportation Research Record: Journal of the Transportation Research Board 2299, Washington, D.C., pp. 41-47 (2012)

\section{Author Biographies}

Sheila Ferrer is a Ph.D. candidate in the Transport Department at Universitat Politècnica de València (Spain). Her research is focused on the understanding of travel behavior and the willingness to adopt sustainable travel patterns.

Tomás Ruiz is Associate Professor in the Transport Department at Universitat Politècnica de València (Spain). He holds a Ph.D. degree in Transportation and his research is focused on the study of the activity-travel scheduling process, the dynamics of travel behavior and the exploration of factors influencing sustainable mobility. 


\section{Appendix}

Table 7 Explanatory Variables

\begin{tabular}{|c|c|}
\hline Variable & Definition \\
\hline \multicolumn{2}{|c|}{ Individual and household characteristics } \\
\hline Gender & 1 female, 0 male \\
\hline Age & $\begin{array}{l}\text { Specific dummy variables: } 18-30 \text { ( } 1 \text { if respondent was born after } 1980 ; 0 \\
\text { otherwise) (ref. category), } 31-50 \text { ( } 1 \text { if respondent was born between 1960- } \\
1979 ; 0 \text { otherwise), More than } 50 \text { ( } 1 \text { if respondent was born before } 1960 ; 0 \\
\text { otherwise) }\end{array}$ \\
\hline Household size & $\begin{array}{l}\text { Number of persons living in the household (including respondent): } 1 \\
\text { member in } \mathrm{HH} \text { (ref. category), } 2 \text { members in } \mathrm{HH}, 3 \text {, more than } 3\end{array}$ \\
\hline Marital status & $\begin{array}{l}\text { Specific dummy variables: Married, Divorced, Unmarried Couple, } \\
\text { Single }\end{array}$ \\
\hline Household position & $\begin{array}{l}\text { Head of household ( } 1 \text { if respondent is head of household; } 0 \text { otherwise) } \\
\text { Sharing a flat ( } 1 \text { if respondent is sharing a flat; } 0 \text { otherwise) } \\
\text { Son/daughter ( } 1 \text { if respondent is son/daughter; } 0 \text { otherwise) }\end{array}$ \\
\hline Education level & $\begin{array}{l}\text { Education level: } 0=\text { Elementary, } 1=\text { Secondary, } 2=\text { Post-secondary no } \\
\text { university level, } 3=\text { Bachelor's degree, } 4=\text { Master's degree or PhD } \\
\text { Specific dummy variables: Elementary ( } 1 \text { if respondent has elementa } \\
\text { education; } 0 \text { otherwise) (Ref. category), Secondary, Post-secondary no } \\
\text { university level, Bachelor's degree, Master's degree or PhD }\end{array}$ \\
\hline Main occupation & $\begin{array}{l}\text { Dummy variables: Working ( } 1 \text { if respondent is working; } 0 \text { otherwise), } \\
\text { Student, Unemployed, Retired }\end{array}$ \\
\hline Secondary occupation & $\begin{array}{l}\text { No secondary occupation ( } 1 \text { if respondent has no secondary occupation; } 0 \\
\text { otherwise) } \\
\text { Working and studying ( } 1 \text { if respondent is working as main occupation and } \\
\text { studying as secondary occupation; } 0 \text { otherwise) } \\
\text { Studying and working ( } 1 \text { if respondents is studying as main occupation and } \\
\text { working as secondary; } 0 \text { otherwise occupation) }\end{array}$ \\
\hline $\begin{array}{l}\text { Number of cars } \\
\text { Car availability } \\
\text { Number of motorbikes }\end{array}$ & $\begin{array}{l}\text { Number of cars in the household: } 1 \text { car, } 2,3 \text {, more than } 3 \\
\text { Car availability during the week: } 0=\text { low, } 1=\text { medium, } 2=\text { high } \\
\text { Number of motorbikes in the household }\end{array}$ \\
\hline Number of bicycles & Number of bicycles in the household \\
\hline $\begin{array}{l}\text { Distance from residence } \\
\text { to city centre of Valencia }\end{array}$ & $\begin{array}{l}\text { Household to city centre }<2.5 \mathrm{~km} \text { ( } 1 \text { if respondent lives less than } 2.5 \mathrm{~km} \\
\text { from the city centre of Valencia; } 0 \text { otherwise) } \\
\text { Household to city centre more than } 2.5 \mathrm{~km}\end{array}$ \\
\hline
\end{tabular}

Characteristics of the activity at origin or at destination / characteristics of the trip

Type of activity

Dummy variables: Basic needs (sleep, breakfast/lunch/dinner and personal care); Work/ study (working, tele-working, attending classes, studying, other 
work or study-related activities), Shopping (grocery, occasional items shopping) (Ref.

\begin{tabular}{ll}
\hline Table 7 (Continued) & \\
\hline Variable & Definition \\
\hline Type of activity & category); Household obligations (cleaning/maintenance, meal preparation, \\
& household member care, drop-off/pick-up household members, attending to \\
& pets and other household tasks); Leisure (cinema/theatre, dining, sports, \\
& strolling or cycling, TV, reading, music, internet surfing); Social (using social \\
& media networks (Facebook, etc.), phoning ( $>10$ min), hosting \\
& relatives/friends, visiting, dropping-off/picking-up non-household members, \\
& social events (weddings, partying, etc.)); Services (hairdressing, banking, \\
& medical appointments, religious services); Other
\end{tabular}

Day of the week

Starting time

Activity duration

Trip duration

Location

Trip companions

Household companions

Non-household companions

Type of scheduling

Type of tour
Day of the week: $0=$ Monday, $1=$ Tuesday, $2=$ Wednesday, $3=$ Thursday, 4=Friday, 5=Saturday, $6=$ Sunday

Specific dummy variables: Monday ( 1 if the act./trip is executed on Monday, 0 otherwise),Tuesday, Wednesday, Thursday, Friday, Saturday, Sunday

Dummy variables: $7-14 \mathrm{~h}$ ( 1 if starting time of act./trip is between 7-14 h, 0 otherwise) (ref. category), 14-19 h, 19-23 h and 23-7 h

Activity duration: $0=$ less than 30 minutes, $1=30-60$ minutes, $2=60-120$ minutes, $3=$ more than 120 minutes

$>120$ min ( 1 if activity duration is longer than 120 minutes, 0 otherwise)

Duration of the trip: $0=$ Less than 6 minutes, $1=$ between $6-12$ minutes, $2=$ between $12-20$ minutes, $3=$ between $20-30$ minutes, $4=$ more than 30 minutes

$>20 \mathrm{~min}$ ( 1 if trip duration is more than 20 minutes, 0 otherwise)

Dummy variables: Home ( 1 if location is home, 0 otherwise); Workplace; Study place; Other

Trip companions ( 1 if the trip is executed with trip companions, 0 otherwise)

Dummy variables: Household companions $=0$ ( 1 if the activity/trip is executed without household members), household companions $=1$, household companions $>1$

Dummy variables: Non-household companions $=0$ ( 1 if the activity/trip is executed without non-household companions), non-household companions $=1$, non-household companions $>1$

Executed as Pre-planned ( 1 if act./trip is executed as pre-planned, 0 otherwise); Modified; Spontaneously added

Home-workplace ( 1 if tour is from home to workplace, 0 otherwise); Homestudy place; Home-other place (other place: different from home, workplace or study place); Workplace-home; Workplace-study place; Workplace-other place; Other place-home; Other place-workplace; Other place-study place; Other place-Other place 
